\title{
FAKTOR-FAKTOR YANG BERHUBUNGAN DENGAN KEJADIAN HYPEREMESIS GRAVIDARUM PADA IBU HAMIL TRIMESTER I DI RUMAH SAKIT UMUM DAERAH KOTA PRABUMULIH
}

\author{
FACTORS RELATED TO GRAVIDARUM HYPEREMESIS EVENTS IN TRIMESTER I \\ PREGNANT MOTHER I IN GENERAL HOSPITAL IN PRABUMULIH
}

\author{
Desti Widya Astuti \\ Akademi Kebidanan Rangga Husada Prabumulih, Sumatera Selatan \\ email:destiwidya.29@gmail.com
}

\begin{abstract}
ABSTRAK
Hyperemesis gravidarum merupakan mual dan muntah yang berlebihan pada wanita hamil sehingga menggangu pekerjaan sehari-hari, Biasanya terjadi pada kehamilan trimester I. Tujuan dari penelitian ini untuk mengetahui faktor-faktor yang berhubungan dengan kejadian hyperemesis gravidarum pada ibu hamil trimester I di rumah sakit umum daerah kota prabumulih tahun 2019. Metode penelitian bersifat analitik, dengan menggunakan pendekatan Cross Sectional. Populasi penelitian ini adalah ibu hamil yang di rawat sebanyak 158 responden di rumah sakit umum daerah kota prabumulih. Jumlah sampel pada penelitian ini adalah 113 responden.Intrumen penelitian berupa data studi rekam medik. Kesimpulan dari penelitian ini ada hubungan yang bermakna dengan kejadian umur dengan hasil statisticp value $0,001<\alpha 0,05$, paritas dengan hasil statistic $p$ value $0,003<\alpha 0,05$, pendidikan dengan hasil statistic $p$ value $0,005<\alpha 0,05$, dan jarak kehamilan dengan hasil statisticp value 0,000 $<\alpha 0,05$, dengan kejadian hyperemesis gravidarum pada ibu hamil trimester I.
\end{abstract}

Kata Kunci: umur, pendidikan, paritas, jarak kehamilan dan hyperemesis gravidarum

\begin{abstract}
Hyperemesis gravidarum is excessive nausea and vomiting in pregnant women so that it interferes with daily work, usually occurs in the first trimester of pregnancy. The purpose of this study was to determine the factors associated with the incidence of hyperemesis gravidarum in pregnant women in the first trimester of the general hospital in the city of Prabumulih.The methode of research was analytic by using cross sectional approach, The population of this study were 158 pregnant women who were treated at the general hospital in the city of Prabumulih, The number of samples in this study were 113 respondents. The instrument of the research was study medical record. The conclusion of this study is that there is a significant relationship with the incidence of age and statistical results $p$ value $0,001<\alpha 0,05$, parity with statistical results $p$ value 0,003 $<\alpha 0,05$, education with statistical results $p$ value $0,005<\alpha 0,05$, and pregnancy interval with p statistical results $p$ value $0,000<\alpha 0,05$, with the incidence of hyperemesis gravidarum in first trimester pregnant women.
\end{abstract}

Keywords: age, education, parity, distance of pregnancy and hyperemesis gravidarum 


\section{PENDAHULUAN}

Kehamilan merupakan suatu proses reproduksi yang perlu perawatan khusus agar dapat berlangsung dengan baik demi tercapainya persalinan yang aman dan melahirkan bayi yang sehat. Komplikasi kehamilan salah satunya adalah mual dan muntah atau dikenal dengan Hyperemesis Gravidarum. Dampak Hyperemesis Gravidarum yaitu dehidrasi yang menimbulkan konsumsi O2 menurun, gangguan fungsi liver dan terjadi ikhterus, terjadi perdarahan pada parenkim liver sehingga menyebabkan gangguan fungsi umum alat-alat vital dan menimbulkan kematian ${ }^{1}$.

Faktor penyebab terjadinya Hiperemesis Gravidarum pada ibu hamil, antara lain umur, paritas, pendidikan dan jarak kehamilan. Bahwa kehamilan dikatakan beresiko tinggi adalah kurang dari 20 tahun dan di atas 35 tahun. Usia di bawah 20 tahun bukan masa yang baik untuk hamil karena organ-organ reproduksi belum sempurna, sedangkan usia 35 tahun keatas mempunyai resiko untuk mengalami komplikasi dalam kehamilan dan persalinan.

Paritas primigravida sering mengalami keluhan mual muntah karena sebagian kecil belum mampu beradaptasi dengan hormon dan pada paritas tinggi cenderung lebih menderita karena jumlah hormon yang dikeluarkan semakin tinggi. Pendidikan merupakan faktor yang mempengaruhi individu seperti pengetahuan dan sikap terhadap kesehatan, sehingga bila pendidikan ibu tinggi maka ibu akan menjaga kesehatannya maupun janinnya. Jarak kehamilan yang ideal kehamilan sekurang-kurangnya 2 tahun, jarak kehamilan yang terlalu dekat menyebabkan ibu mempunyai waktu singkat untuk memulihkan kondisi rahimnya agar bisa kembali ke kondisi sebelumnya ${ }^{1}$.
World Health Organization (WHO) memperkirakan angka kematian ibu sebesar 500.000 jiwa dan angka kematian bayi sebesar 10 juta jiwa setiap tahun. Kejadian kematian ibu dan bayi sebagian terdapat di negara berkembang yaitu sebesar 98\%-99\% dimana kematian ibu dan bayi di negara berkembang 100\% lebih tinggi dibandingkan dengan negara maju ${ }^{1}$.

Angka Kematian Ibu (AKI) di Indonesia telah mengalami penurunan dari tahun 2015 diperoleh angka kematian ibu sebanyak 4.999, tahun 2016 diperoleh angka kematian ibu 4.912 dan pada tahun 2017 angka kematian ibu mengalami penurunan menjadi 4.295 kematian (SUPAS data rutin, Kemenkes 2018). Angka kematian ibu di Provinsi Sumatera Selatan tahun 2017 (semester I) sebanyak 1.712 kasus. Angka kematian ibu tahun 2018 turun menjadi 120 kasus dan tahun 2019 menjadi 69 kasus $^{2}$.

Berdasarkan data dari rekam medis rumah sakit umum daerah kota prabumulih untuk tiga tahun terakhir kasus hyperemesis gravidarum mengalami peningkatan dilihat dari tahun 2017 terdapat 102 orang $(83,6 \%)$ yang mengalami hyperemsis gravidarum dari $122 \mathrm{ibu}$ hamil, pada tahun 2018 terdapat 105 orang $(79,5 \%)$ yang mengalami hyperemesis gravidarum dari 132 ibu hamil dan pada tahun 2019 terdapat 127 orang $(80,4 \%)$ yang mengalami hyperemesis gravidarum dari 158 ibu hamil $^{3}$.

Penelitian ini secara umum bertujuan untuk mengetahui faktor-faktor yang berhubungan dengan kejadian Hiperemesis Gravidarum di rumah sakit umum daerah kota prabumulih. 


\section{METODE PENELITIAN}

Metode yang digunakan adalah survey analitik dengan pendekatan Cross Sectional yakni dimana data yang menyangkut variabel dependen (Hyperemesis Gravidarum), dan variabel independen (Umur, Pendidikan, Paritas dan Jarak Kehamilan).Dikumpulkan dalam waktu bersamaan ${ }^{4}$.

Populasi penelitian ini yaitu ibu hamil yang dirawat yang berjumlah 158 orang di Rumah Sakit Umum Daerah Kota Prabumulih, Pengambilan sampel pada penelitian ini menggunakan metode Random Sampling Dengan menggunakan rumus notoadmodjo.

$$
n=\frac{\mathrm{N}}{1+\mathrm{N}(\mathrm{d})^{2}}
$$

Berdasarkan rumus di atas, maka didapatkan jumlah sampel sebesar 113 responden. Cara pengambilan sampel dilakukan dengan mengambil pada bulan april tahun 2020, data yang di peroleh yaitu data sekunder data yang didapatkan dari suatu lembaga instansi dalam penelitian ini data sekunder diperoleh dari data rekam medik rumah sakit umum daerah kota prabumulih.

\section{HASIL}

\section{Analisis Univariat}

Analisa ini untuk mengetahui distribusi frekuensi dan persentase dari tiap variabel independen (Umur, Pendidikan, Paritas dan Jarak Kehamilan) serta variabel dependen (Kejadian Hyperemesis Gravidarum). Data distribusi dalam bentuk tabel dan teks akan diuraikan sebagai berikut:

Tabel 1. Distribusi Frekuensi Responden berdasarkan Kejadian Hyperemesis Gravidarum di Rumah Sakit Umum Daerah Kota Prabumulih

\begin{tabular}{lcc}
\hline Kejadian Hyperemesis Gravidarum & Frekuensi & $\mathbf{\%}$ \\
\hline Ya & 97 & 85,8 \\
Tidak & 16 & 14,2 \\
\hline Jumlah & $\mathbf{1 1 3}$ & $\mathbf{1 0 0}$ \\
\hline
\end{tabular}

Dari tabel di atas diketahui bahwa dari 113 responden didapatkan sebanyak 97 $(85,8 \%)$ responden yang didiagnosa mengalami hyperemesis gravidarum dan sebanyak $16(14,2 \%)$ responden yang tidak didiagnosa mengalami hyperemesis gravidarum.

Tabel 2.Distribusi Frekuensi Responden Umur Ibu di Rumah Sakit Umum Daerah Kota Prabumulih

\begin{tabular}{ccc}
\hline Umur & Frekuensi & \% \\
\hline Beresiko & 68 & 60,2 \\
Tidak Beresiko & 45 & 29,8 \\
\hline Jumlah & $\mathbf{1 1 3}$ & $\mathbf{1 0 0}$ \\
\hline
\end{tabular}

Dari tabel di atas diketahui bahwa dari 113 responden didapatkan bahwa responden yang umur beresiko sebanyak 68 responden $(60,2 \%)$ dan responden yang umur tidak beresiko sebanyak 45 responden 
Tabel 3. Distribusi Frekuensi Responden Pendidikan Ibu di Rumah Sakit Umum Daerah Kota Prabumulih

\begin{tabular}{lcc}
\hline Pendidikan & Frekuensi & \% \\
\hline Pendidikan Tinggi & 68 & 60,2 \\
Pendidikan Rendah & 45 & 39,8 \\
\hline Jumlah & $\mathbf{1 1 3}$ & $\mathbf{1 0 0}$ \\
\hline
\end{tabular}

Dari tabel di atas diketahui bahwa dari 113 responden didapatkan bahwa responden yang berpendidikan tinggi sebanyak 68

responden $(60,2 \%)$ dan responden yang berpendidikan rendah sebanyak 45 responden $(39,8 \%)$.

Tabel 4. Distribusi Frekuensi Responden Paritas Ibu di Rumah Sakit Umum Daerah Kota Prabumulih Tahun 2019

\begin{tabular}{lcc}
\hline Paritas & Frekuensi & \% \\
\hline Risiko Tinggi & 75 & 66,4 \\
Risiko Rendah & 38 & 33,6 \\
\hline Jumlah & $\mathbf{1 1 3}$ & $\mathbf{1 0 0}$ \\
\hline
\end{tabular}

Dari tabel di atas diketahui bahwa dari 113 responden didapatkan bahwa responden paritas risiko tinggi sebanyak 75 responden $(66,4 \%)$ dan responden paritas risiko rendah sebanyak 38 responden $(33,6 \%)$.

Tabel 5. Distribusi Frekuensi Responden Jarak Kehamilan di Rumah Sakit Umum Daerah Kota Prabumulih

\begin{tabular}{lcc}
\hline Jarak Kehamilan & Frekuensi & \% \\
\hline Resiko Tinggi & 67 & 59,3 \\
Resiko Rendah & 46 & 40,7 \\
\hline Jumlah & $\mathbf{1 1 3}$ & $\mathbf{1 0 0}$ \\
\hline
\end{tabular}

Dari tabel di atas diketahui bahwa dari 113 responden didapatkan bahwa responden yang jarak kehamilan resiko tinggi sebanyak 67 responden $(59,3 \%)$ dan responden yang jarak kehamilan resiko rendah sebanyak 46 responden $(40,7 \%)$.
Hasil Analisis Bivariat

Analisis Bivariat untuk menilai apakah ada hubungan antara variable bebas yaitu, Umur, Pendidikan, Paritas dan Jarak kehamilan, dengan variable terikat dengan kejadian hyperemesis gravidarum dapat dilihat pada uraian di bawah ini. 
Tabel 6. Hubungan Umur, Pendidikan, Paritas, dan Jarak Kehamilan Dengan Kejadian Hyperemesis Gravidarum Pada Ibu Hamil Trimester I di Rumah Sakit Umum Daerah Kota Prabumulih.

\begin{tabular}{|c|c|c|c|c|c|c|c|}
\hline \multirow{3}{*}{ Variabel } & \multicolumn{6}{|c|}{ Hyperemesis Gravidarum } & \multirow{3}{*}{$P$ Value } \\
\hline & \multicolumn{2}{|c|}{$\mathbf{Y a}$} & \multicolumn{2}{|c|}{ Tidak } & \multicolumn{2}{|c|}{ Jumlah } & \\
\hline & $\mathbf{n}$ & $\%$ & $\mathbf{n}$ & $\%$ & $\mathbf{N}$ & $\%$ & \\
\hline \multicolumn{8}{|l|}{ Umur Ibu } \\
\hline Beresiko & 65 & 57,5 & 3 & 2,7 & 68 & 60,2 & $0,001 *$ \\
\hline Tidak Beresiko & 32 & 28,3 & 13 & 11,5 & 45 & 39,8 & \\
\hline \multicolumn{8}{|l|}{ Pendidikan Ibu } \\
\hline Pendidikan Tinggi & 64 & 56,6 & 4 & 3,5 & 68 & 60,2 & $0,005^{*}$ \\
\hline Pendidikan Rendah & 33 & 29,2 & 12 & 10,6 & 45 & 39,8 & \\
\hline \multicolumn{8}{|l|}{ Paritas Ibu } \\
\hline Resiko Tinggi & 70 & 61,9 & 5 & 4,4 & 75 & 66,4 & $0,003^{*}$ \\
\hline Resiko Rendah & 27 & 23,9 & 11 & 9,7 & 38 & 33,6 & \\
\hline \multicolumn{8}{|l|}{ Jarak Kehamilan } \\
\hline Resiko Tinggi & 63 & 55,8 & 4 & 3,5 & 67 & 59,3 & $0,000^{*}$ \\
\hline Resiko Rendah & 34 & 30,1 & 12 & 10,6 & 46 & 40,7 & \\
\hline
\end{tabular}

Tabel 6. menunjukkan pada umur ibu yang beresiko ternyata lebih banyak ditemukan reponden dengan kejadian hyperemesis gravidarum $(57,5 \%)$, dari pada responden dengan kejadian hyperemesis gravidarum yang tida beresiko (2,7\%). Sementara umur ibu yang tidak beresiko ternyata lebih banyak ditemukan responden dengan kejadian responden hyperemesis gravidarum $(28,3 \%)$, dari pada responden hyperemesis gravidarum yang tidak beresikok sebanyak (11,5\%). Berdasarkan hasil analisa bivariat dengan uji statistik mengunakan Chi-Square didapatkan hasil $p$ value $=0,001 \quad(p \leq 0,05)$ berarti hipotesis menyatakan bahwa ada hubungan yang bermakna antara Umur Ibu dengan Kejadian Hyperemesis Gravidarum terbukti.

Menunjukkan pada Pendidikan ibu yang berpendidikan tinggi ternyata lebih banyak ditemukan reponden dengan kejadian hyperemesis gravidarum $(56,6 \%)$, dari pada responden dengan kejadian hyperemesis gravidarum yang tidak pendidikan tinggi (3,5\%). Sementara pendidikan ibu yang pendidikan rendah ternyata lebih banyak ditemukan responden dengan kejadian responden hyperemesis gravidarum $(29,2 \%)$, dari pada responden hyperemesis gravidarum yang tidak pendidikan rendah $(10,6 \%)$.Berdasarkan hasil analisa bivariat dengan uji statistik mengunakan ChiSquare didapatkan hasil $p$ value $=0,005$ ( $p \leq 0,05$ ) berarti hipotesis menyatakan bahwa ada hubungan yang bermakna antara Pendidikan Ibu dengan Kejadian Hyperemesis Gravidarum terbukti

Menunjukkan pada paritas yang resiko tinggi ternyata lebih banyak ditemukan reponden dengan kejadian hyperemesis gravidarum $(61,9 \%)$, dari pada responden dengan kejadian hyperemesis gravidarum yang tidak resiko tinggi (4,4\%). Sementara paritas ibu yang resiko rendah ternyata lebih banyak ditemukan responden dengan kejadian responden hyperemesis gravidarum $(23,9 \%)$, dari pada responden hyperemesis gravidarum yang tidak resiko rendah $(9,7 \%)$. Berdasarkan hasil analisa bivariat dengan uji statistik mengunakan Chi-Square didapatkan hasil $p$ value $=$ $0,003$ ( $p \leq 0,05)$ berarti hipotesis menyatakan bahwa ada hubungan yang bermakna antara Paritas Ibu dengan Kejadian Hyperemesis Gravidarum terbukti. 
Menunjukkan pada Jarak kehamilan yang resiko tinggi ternyata lebih banyak ditemukan reponden dengan kejadian hyperemesis gravidarum $(55,8 \%)$, dari pada responden dengan kejadian hyperemesis gravidarum yang tidak resiko tinggi $(3,5 \%)$. Sementara jarak kehamilan ibu yang resiko rendah ternyata lebih banyak ditemukan responden dengan kejadian responden hyperemesis gravidarum $(30,1 \%)$, dari pada responden hyperemesis gravidarum yang tidak resiko rendah $(10,6 \%)$. Berdasarkan hasil analisa bivariat dengan uji statistik mengunakan Chi-Square didapatkan hasil $p$ value = $0,006 \quad(p \leq 0,05)$ berarti hipotesis menyatakan bahwa ada hubungan yang bermakna antara Jarak Kehamilan dengan Kejadian Hyperemesis Gravidarum terbukti.

\section{PEMBAHASAN}

Gambaran Umum, Umur Ibu, Pendidikan Ibu, Paritas Ibu dan Jarak Kehamilan di Rumah Sakit Umum Daerah Kota Prabumulih

Pada pengumupulan data didapatkan bahwa umur ibu dikategorikan menjadi kelompok umur berisiko (bila usia ibu < 20 tahun dan > 35 tahun) dan umur tidak berisiko (bila usia ibu 20-35 tahun). Pada analisa univariat diketahui bahwa dari 113 responden didapatkan bahwa responden yang umur beresiko sebanyak 68 responden $(60,2 \%)$ dan responden yang umur tidak beresiko sebanyak 45 responden $(29,8 \%)$.

variabel Pendidikan dibedakan menjadi kelompok Pendidikan Tinggi (Bila pendidikan ibu $\geq$ SMA) dan Pendidikan Rendah (Bila pendidikan ibu < SMA). Hasil analisa univariat diketahui bahwa dari 113 responden didapatkan bahwa responden yang berpendidikan tinggi sebanyak 68 responden $(60,2 \%)$ dan responden yang berpendidikan rendah sebanyak 45 responden $(39,8 \%)$.

variabel Paritas dikategorikan menjadi kelompok Risiko Tinggi (Bila jumlah anak 1 dan > 3) dan Risiko Rendah (Bila jumlah anak 2 dan 3). Pada analisa univariat diketahui dari 113 responden didapatkan bahwa responden paritas risiko tinggi sebanyak 75 responden $(66,4 \%)$ dan responden paritas risiko rendah sebanyak 38 responden $(33,6 \%)$.

variabel Jarak Kehamilan Ibu dibedakan menjadi kelompok Resiko tinggi (Bila jarak kehamilan $<2$ tahun) dan Resiko rendah (bila jarak kehamilan $\geq 2$ tahun). Pada analisa univariat diketahui bahwa dari 113 responden didapatkan bahwa responden yang jarak kehamilan resiko tinggi sebanyak 67 responden $(59,3 \%)$ dan responden yang jarak kehamilan resiko rendah sebanyak 46 responden $(40,7 \%)$.

Penelitian ini sejalan dengan peneliti fitri muriyasi dkk, tahun 2017 dengan judul fator-faktor yang berhubungan dengan kejaidan hiperemesis gravidarum di RSU Muhamamdiyah metro, dengan hasil statistikmenunjukkan bahwa ada hubungan umur ibu dengan kejadian hiperemesis gravidarum dengan $\mathrm{p}$-value $0,002<0,05$, ada hubungan paritas dengan kejadian hiperemesis gravidarum dengan $\mathrm{p}$-value $0,008<0,05$ dan ada hubungan usia kehamilan dengan kejadian hiperemesis gravidarum pada usia kehamilan dengan $\mathrm{p}$ value $0,006<0,05$.

Hubungan Umur Ibu dengan Kejadian Hyperemesis Gravidarum

Berdasakan Hasil uji statistik mengunakan Chi-Square didapatkan hasil $p$ value $=$ $0,001$ ( $p \leq 0,05)$ berarti hipotesis menyatakan bahwa ada hubungan yang bermakna antara Umur Ibu dengan Kejadian Hyperemesis Gravidarum terbukti. 
Penelitian ini sejalan dengan penelitian yang dilakukan oleh Hertje (2013) di Puskesmas Tompaso Kabupaten Minahasa didapatkan faktor-faktor yang berhubungan dengan kejadian hyperemesis gravidarum yaitu umur, pendidikan, paritas dan jarak kehamilan. Hal ini dapat dilihat dari hasil penelitian $\mathrm{p}$ value $<0,05$ bahwa ada hubungan antara umur dengan kejadian emesis gravidarum dengan nilai $\mathrm{p}$ $=0,001$.

Menurut hertje, Bahwa kehamilan dikatakan beresiko tinggi adalah kurang dari 20 tahun dan diatas 35 tahun.Usia dibawah 20 tahun bukan masa yang baik untuk hamil karena organ-organ reproduksi belum sempurna, sedangkan usia 35 tahun keatas mempunyai resiko untuk mengalami komplikasi dalam kehamilan dan persalinan.

Hamil diusia muda merupakan salah satu factor penyebab terjadinya hyperemesis gravidarum, dalam kurun waktu reproduksi sehat bahwa umur yang aman untuk kehamilan dan persalinan yaitu pada umur 20 dampai dengan 30 tahun. Kematian maternal pada wanita hamil dan melahirkan pada usia 20sampai dengan 29 tahun, kematian maternal meningkat kembali sesudah umur 30 sampai dengan 35 tahun, hal ini disebabkan menurunya fungsi organ reproduksi wanita ${ }^{5}$.

Hubungan Pendidikan Ibu dengan Kejadian Hyperemesis Gravidarum

Berdasarkan Hasil uji statistik mengunakan Chi-Square didapatkan hasil $p$ value $=0,005(p \leq 0,05)$ berarti hipotesis menyatakan bahwa ada hubungan yang bermakna antara Pendidikan Ibu dengan Kejadian Hyperemesis Gravidarum terbukti.

Penelitian ini sejalan dengan penelitian yang dilakukan oleh Hertje di Puskesmas Tompaso Kabupaten Minahasa didapatkan faktor-faktor yang berhubungan dengan kejadian hyperemesis gravidarum yaitu umur, pendidikan, paritas dan jarak kehamilan. Hal ini dapat dilihat dari hasil penelitian $\mathrm{p}$ value $<0,05$ bahwa ada hubungan antara pendidikan dengan kejadian emesis gravidarum dengan nilai $\mathrm{p}$ $=0,000$. Dapat dilihat dari hasil penelitian $\mathrm{p}$ value $<0,05$ bahwa ada hubungan antara pendidikan dengan kejadian emesis gravidarum dengan nilai $\mathrm{p}=0,001$.

Bahwa pendidikan merupakan faktor yang mempengaruhi individu seperti pengetahuan ibu, sikap ibu terhadap kesehatan serta tingkat pendidikan. Dimana untuk berprilaku kesehatan misalnya (pemeriksaan kesehatan bagi ibu hamil) diperlukan pengetahuan tentang manfaat periksa hamil, baik bagi kesehatan ibu maupun bagi janinya ${ }^{6}$.

Hubungan Paritas dengan Kejadian Hyperemesis Gravidarum

Berdasarkan Hasil uji statistik mengunakan Chi-Square didapatkan hasil $p$ value $=0,003(p \leq 0,05)$ berarti hipotesis menyatakan bahwa ada hubungan yang bermakna antara Paritas Ibu dengan Kejadian Hyperemesis Gravidarum terbukti.

Penelitian ini sejalan dengan penelitian yang dilakukan oleh Ruri dan Nurul (2014) menyatakan terdapat hubungan antara paritas dengan kejadian hyperemesis gravidarum di RSUD Dr. Adjidarmo Rangkasbitung tahun 2014, bahwa nilai $\mathrm{p}$ value $=0,002$ menyatakan bahwa ada hubungan antara paritas dengan kejadian hyperemesis gravidarum ${ }^{7}$.

Menurut peneliti dari hasil penelitian yang dilakukan di RSUD kota prabumulih ada hubungan bermakna antara paritas ibu dengan kejadian hyperemesis gravidarum bahwa paritas primigravida sering mengalami keluhan mual muntah karena 
sebagian kecil belum mampu beradaptasi dengan hormon dan pada paritas tinggi cenderung lebih menderita karena jumlah hormon yang dikeluarkan semakin tinggi.

Beberapa hasil penelitian ini dimungkinkan karena sebagian besar responden mengalami paritas primigravida sehingga keluhan mualdan muntah seringkali ditemukan. Pada wanita primigravida, sebagian kecil belum mampu beradaptasi dengan hormon dan pada usia lebih tua juga cenderung lebih menderita karena jumlah hormon yang dikeluarkan semakin tinggi, dan riwayat kehamilan sebelumnya juga dapat mempengaruhi kehamilannya sekarang.

Hubungan Jarak Kehamilan Ibu dengan Kejadian Hyperemesis Gravidarum

Berdasarkan Hasil uji statistik mengunakan Chi-Square didapatkan hasil $p$ value $=0,006(p \leq 0,05)$ berarti hipotesis menyatakan bahwa ada hubungan yang bermakna antara Jarak Kehamilan dengan Kejadian Hyperemesis Gravidarum terbukti.

Penelitian ini sejalan dengan penelitian yang dilakukan oleh Hertje di Puskesmas Tompaso Kabupaten Minahasa didapatkan faktor-faktor yang berhubungan dengan kejadian hyperemesis gravidarum yaitu umur, pendidikan, paritas dan jarak kehamilan. Hal ini dapat dilihat dari hasil penelitian $\mathrm{p}$ value $<0,05$ bahwa ada hubungan antara jarak kehamilan dengan kejadian emesis gravidarum dengan nilai $\mathrm{p}$ $=0,001$.

Sesuai teori bahwa jarak ideal kehamilan sekurang-kurangnya 2 tahun. Menurut Rofiq proporsi kematian terbanyak terjadi pada ibu dengan prioritas 1-3 anak dan jika dilihat dari jarak kehamilannya ternyata jarak kurang dari 2 tahun menunjukan proporsi kematian maternal lebih banyak. Jarak kehamilan yang terlalu dekat menyebabkan ibu mempunyai waktu singkat untuk memulihkan kondisi rahimnya agar bisa kembali ke kondisi sebelumnya ${ }^{8}$.

\section{KESIMPULAN}

Ada hubungan yang bermakna ( $p$ value $0,001)$ antara umur dengan kejadian hyperemesis gravidarum ibu hamil trimester I di rumah sakit umum daerah kota prabumulih.

Ada hubungan yang bermakna ( $p$ value 0,005) antara pendidikan ibu dengan kejadian hyperemesis gravidarum ibu hamil trimester I di rumah sakit umum daerah kota prabumulih.

Ada hubungan yang bermakna ( $p$ value 0,003 ) antara paritas ibu dengan kejadian hyperemesis gravidarum ibu hamil trimester I di rumah sakit umum daerah kota prabumulih.

Ada hubungan yang bermakna ( $p$ value 0,000 ) antara jarak kehamilan dengan kejadian hyperemesis gravidarum ibu hamil trimester I di rumah sakit umum daerah kota Prabumulih.

\section{SARAN}

Kepada Ibu hamil sebagai reponden yang mengalami Hiperemesis Gravidarum, hendaknya penelitian ini memberi masukan agar lebih meningkatkan dan memanfaatkan pelayanan kesehatan yang ada.

Peningkatan pelayanan bisa dalam bentuk pemberian informasi diantaranya melalui penyuluhan demi meningkatkan pemahaman ibu hamil bahwa ada berbagai faktor yang berkorelasi dengan kejadian Hiperemesis Gravidarum. Peneliti juga sebagai bidan telah mendapat masukan yang berharga dalam pelayanan kepada ibu hamil yang sedang mengalami Hiperemesis Gravidarum bahwa dalam 
CENDEKIA MEDIKA

p-ISSN: 2503-1392

e-ISSN: 2620-5424

pelayanan sangat perlu untuk memperhatikan faktor-faktor yang ada pada ibu hamil sehingga kualitas pelayanan sebagai bidan akan makin baik.

\section{DAFTAR PUSTAKA}

1. Herrel, Ernest Howard. 2013. Nausea and Vomiting of Pregnancy. American Family Physician89 (12):965-970.

2. Lesti.2005.Persalinanhttp//files.wordp ress.com/2008/04/salinrumah.pdf.Dia kses tanggal 21 november 2014

3. Rekam Medik Rumah Sakit Umum Daerah Kota Prabumulih 2020

4. Notoadmodjo. 2014. Metodelogi Penelitian Kesehatan.Jakarta : Renieka Cipta

5. Wiknjosastro, 2010. Buku Acuan Pelayanan Maternal dan Neonatal. Jakarta : PT. Bina Pustaka Sarwono Prawirohardjo

6. Sumujatun dkk. Konsep dasar keperawatan komunitas. Jakarta EGC; (2010)

7. Ruri. (2014). Penatalaksanaan Terapi Latihan pada Kondisi PostOperasi Fraktur Femur 1/3 Distal Dextra dengan Pemasangan Plate and Screw. Karya Tulis Ilmiah. diunduh melalui eprints.ums.ac.id pada tanggal 22 Januari 2018.
8. Rofiq. 2015. Psikologi Implementasinya Dalam Manajemen Lapangan. Jakarta : CV Sinar Mas 